\title{
Tricuspid atresia: Experience in surgical management with a modified cavopulmonary anastomosis
}

\author{
G. A ZZOLINA, S. EUFRATE, a nd P. PENSA \\ Department of Paediatric Cardiothoracic Surgery, Ospedale Generale Provinciale, Massa, Italy
}

\begin{abstract}
A limited experience with an initial series of nine patients operated upon for tricuspid atresia using a modified superior vena cava to right pulmonary artery anastomosis is presented. The modified technique is described and illustrated. It avoids permanent disruption of pulmonary artery continuity and the high incidence of superior vena cava syndrome. In short, the right pulmonary artery is not severed, the azygos vein is always ligated, the superior vena cava is not mass ligated and is subjected to delayed interruption.

Analysis of the results shows an operative and overall mortality of $33 \%$. The advantages of this modified surgical approach are outlined.
\end{abstract}

Recent reports indicate that superior vena cava to pulmonary artery anastomosis (Glenn, 1958; Glenn and Patiño, 1954) is becoming the preferred operation in tricuspid atresia. First suggested by Carlon, Mondini, and De Marchi (1951), it has undergone several modifications. Two major drawbacks are the permanent disruption of a main structure, namely the right pulmonary artery, and the high incidence of superior vena cava syndrome reported to occur in $35 \%$ of cases (Edwards and Bargeron, 1970).

Permanent disruption of the right pulmonary artery continuity may not be of paramount importance at present but it may become so in the future. Nonetheless, when used in tetralogy of Fallot, the Glenn operation renders total correction more difficult and bars normal anatomical reconstruction.

One of us (G. A.) has devised a modification of the superior vena cava to pulmonary artery anastomosis. This is a report on a limited initial series of patients illustrating the evolution of the technical modification and our experience in the surgical treatment of tricuspid atresia.

\section{MODIFIED TECHNIQUE}

No claim of originality in the conception of the procedure itself is made. We are simply illustrating the efforts of one of us (G. A.) to solve in the most rational fashion some of the short-comings in our hands of this very valuable procedure both as shortand long-term follow-up.
SUPERIOR VENA CAVA TO RIGHT PULMONARY ARTERY ANASTOMOSIS A standard right anterolateral ribspreading thoracotomy incision in the fourth interspace is made and the right lung is retracted. After incision of the pericardium the superior vena cava and right pulmonary artery are carefully dissected out and extensively mobilized in order to permit the effortless overlapping of the superior vena cava over the right pulmonary artery where it branches out from the main trunk. A looped heavy silk thread is placed to secure the artery distally where the peripheral branches originate. An exclusion clamp is placed to encompass the right pulmonary artery (most proximal portion) and the adjacent superior vena cava which is rotated anteriorly so that the anastomosis may be performed in its posterior aspect. Two 000000 black silk sutures are placed (and tied) at the corners of the proposed incisions. These are made one on each vessel and parallel to each other (Fig. 1). A portion of vessel wall in the shape of a triangle is removed from one vessel. The length of the incision is such that approximately half the circumference of the right pulmonary artery is included in the anastomotic line. The anastomosis is performed with a running suture on the posterior and interrupted sutures on the anterior aspects of the stoma to allow growth (Figs. 2 and 3). The looped silk control on the distal right pulmonary artery and the exclusion clamp are removed. The azygos vein is identified, isolated, and ligated (Fig. 4). A straight vascular clamp is placed in an anteroposterior direction to close the superior vena cava at its entrance into the right atrium. A to and fro running suture of 0000 vascular Tevdek ${ }^{1}$ is placed transversely across the superior vena cava

1Braided polyester fibre: brand of Deknatel 


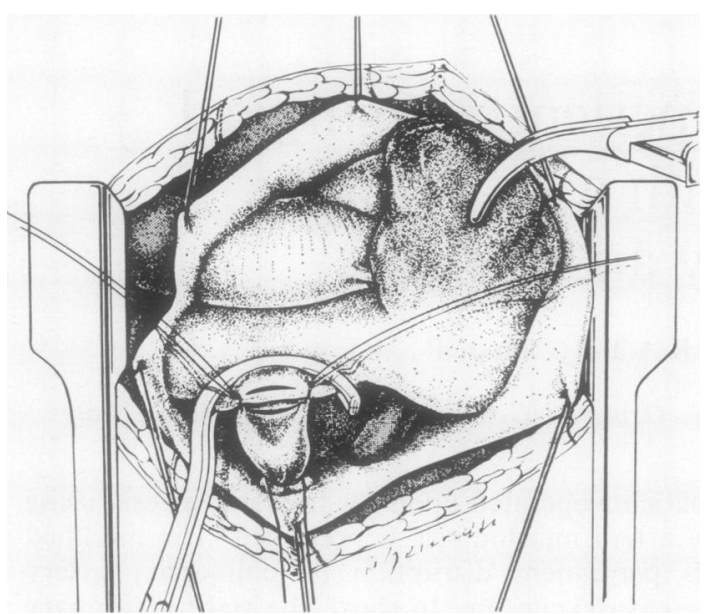

FIG. 1. Side-to-side anastomosis between the superior vena cava and right pulmonary artery. The parallel incisions on the two vessels have been made. The continuity of the right pulmonary artery is preserved.

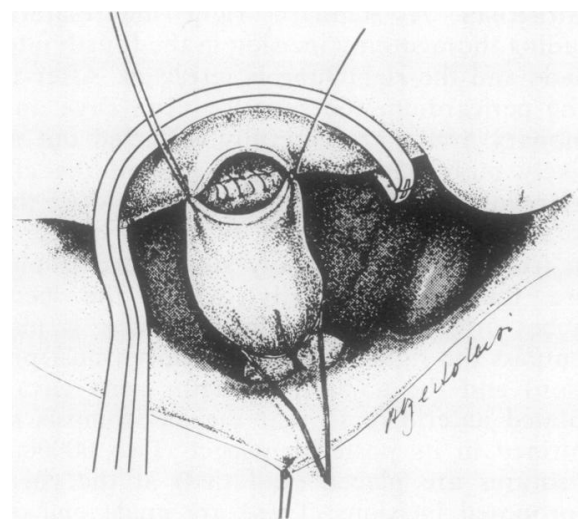

FIG. 2. Detail of the anastomosis. The stoma involves approximately the entire width $(50 \%$ of the circumference) of the right pulmonary artery. The posterior row consists of a continuous suture.

along the clamp so as to occlude effectively the vessel. However, a variation has been introduced at this stage in that approximately one-quarter to one-third of the superior vena cava is left unoccluded. Around this portion a double strand of 000 Tevdek $^{1}$ is placed (Fig. 5) as a double loop, and the two free ends are brought out of the anterior chest wall and left free. From 7 to 14 days later the two threads can be pulled up, thereby shutting off the patent portion of superior vena cava, and tied to one another in the subcutaneous layer where the knot remains buried.

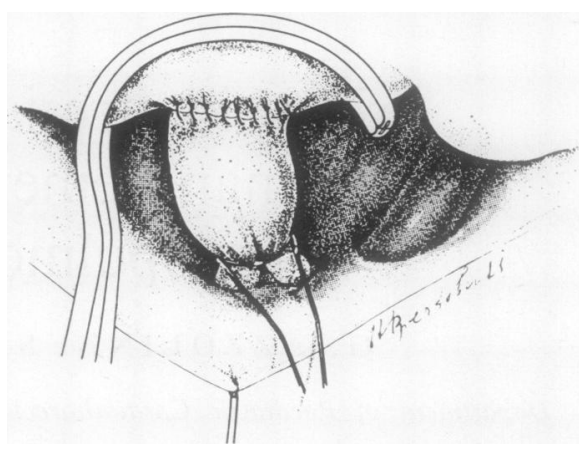

FIG. 3. Detail of the anastomosis. The anastomosis is completed with an anterior interrupted suture line.

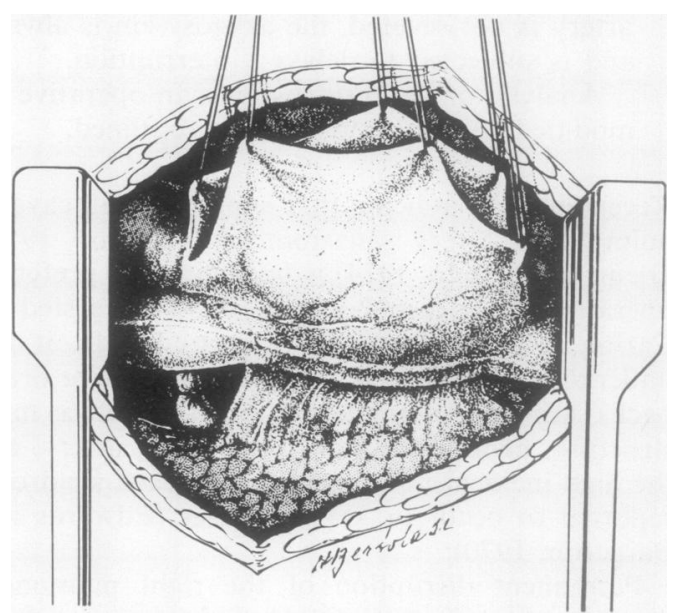

FIG. 4. The azygos vein is identified and doubly ligated.

Pressures in both the superior vena cava and right pulmonary artery are taken during the procedure if warranted.

The pericardium and chest are closed and the latter is drained in the usual manner.

As it is seldom possible to enter the pulmonary artery at cardiac catheterization, estimations of pulmonary artery pressure are made at operation. For cavopulmonary anastomosis to be successful the pressure in the right pulmonary artery should not exceed $20 \mathrm{mmHg}$ and its diameter should not be less than half that of the superior vena cava. If these requirements are not met, a Waterston type of shunt is performed. Recently we have proceeded to ligation or tight banding of the main pulmonary artery where the intraluminal pressure exceeds $20 \mathrm{mmHg}$. If an acceptable reduction in pressure is obtained a cavopulmonary anastomosis is performed. 


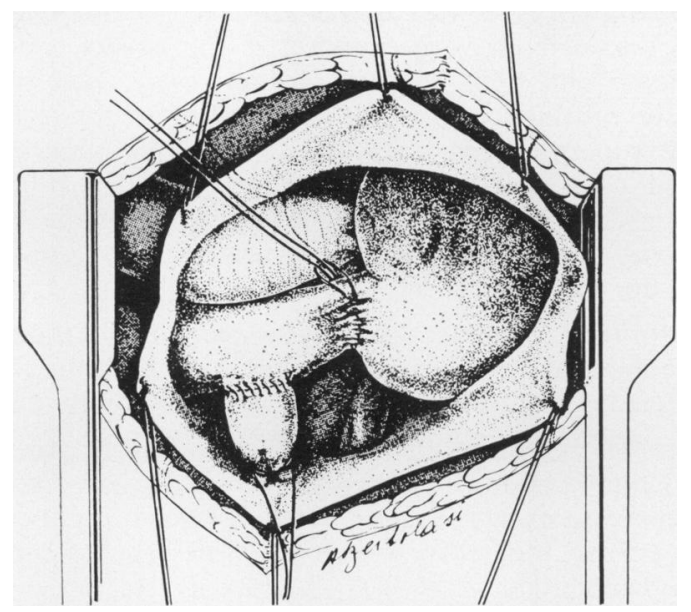

FIG. 5. The side-to-side superior vena cava to pulmonary artery anastomosis has been completed. The superior vena cava has been partially closed in an antero-posterior direction with $a$ to and fro suture leaving approximately one-quarter to one-third of its width unoccluded. Around this portion a loop ligature has been passed for delayed ligature. The two ligature strands are brought out of the chest wall in a more vertical direction than is represented on the drawing.

\section{MATERIAL AND METHODS}

Nine patients, two males and seven females, were consecutively operated upon for the correction of tricuspid atresia during the period 18 April 1968 to
15 July 1970, using the technique of modified superior vena cava to pulmonary artery anastomosis as described. The follow-up rate has been $100 \%$ and the minimum observation period eight months.

In the Table age, sex, body weight, haematocrit, diagnosis, operation and early and late results are listed. The indicated haematocrit for each patient is the last preoperative value. In patients whose haematocrit is above $60 \%$, our group carries out venesection commensurate with the degree of cyanosis and replacement with low molecular weight dextran, generally during blood withdrawals for laboratory examinations, every three or four days. The replacement with dextran is given in the variable amount of $1.0-1.5 \mathrm{ml} / \mathrm{kg}$ body weight (Pensa, Azzolina, and Eufrate, 1968). This practice obtains modest and temporary lowering of the haematocrit.

Four cases $(44 \%)$ presented with a body weight at least $25 \%$ below the normal expected for age and sex.

\section{RESULTS AND CONCLUSIONS}

Preliminary results (Table) concerning nine patients subjected to superior vena cava to pulmonary artery anastomosis with the technique previously described show three operative deaths. In one of these a severe superior vena cava syndrome was apparent for a variable period of time before death. This patient aged 5 years showed radiographic evidence of massive interstitial oedema of the right lung: reoperation for the purpose of untying the azygos vein nine days after the original cavopulmonary anastomosis confirmed the radio-

T A B L E

TRICUSPID ATRESIA

\begin{tabular}{|c|c|c|c|c|c|c|c|c|c|c|c|}
\hline \multicolumn{2}{|c|}{ Patient } & Sex & Diagnosis & $\begin{array}{l}\text { Age } \\
(\mathbf{y r})\end{array}$ & $\begin{array}{c}\begin{array}{c}\text { Body } \\
\text { weight } \\
(\mathbf{k g})\end{array} \\
\end{array}$ & $\begin{array}{c}\text { Haem- } \\
\text { atocrit } \\
\%\end{array}$ & \multicolumn{2}{|c|}{ Operation and Date } & \multirow{2}{*}{$\begin{array}{l}\text { Complication } \\
\begin{array}{l}\text { Rt. pleural } \\
\text { effusion }\end{array}\end{array}$} & \multirow{2}{*}{$\begin{array}{l}\text { Operative } \\
\text { Mortality } \\
\text { Survived }\end{array}$} & Cause of Death \\
\hline 1 & V.G. & & $\begin{array}{l}\text { Tricuspid } \\
\text { atresia }\end{array}$ & 5 & $15 \cdot 500$ & 63 & Modified Glenn' & May $69^{\circ}$ & & & \\
\hline 2 & B.I. & $\mathbf{F}$ & $\begin{array}{l}\text { Tricuspid } \\
\text { atresia }\end{array}$ & 11 & $26 \cdot 000$ & 70 & Modified Glenn' & Sept. 69 & & Survived & \\
\hline 3 & S.E. & $\mathbf{F}$ & Tricuspid & 15 & $9 \cdot 800$ & 52 & Modified Glenn" & Nov. 69 & SVC syndrome & Survived & \\
\hline 4 & E.E. & $\mathbf{F}$ & $\begin{array}{l}\text { Tricuspid } \\
\text { atresia }\end{array}$ & 6 & $15 \cdot 000$ & 70 & Modified Glenn & Dec. 69 & it & Survived & \\
\hline 5 & B.S. & $\mathbf{F}$ & $\begin{array}{l}\text { Tricuspid } \\
\text { atresia }\end{array}$ & $\begin{array}{c}5 \\
\text { mth }\end{array}$ & 3.000 & 63 & $\begin{array}{l}\text { Modified Glenn } \\
\text { Azygos ligature }\end{array}$ & Feb. 70 & $\begin{array}{l}\text { Rt. severe } \\
\text { pulmonary }\end{array}$ & $\begin{array}{l}\text { 1st POD: } \\
\text { Died }\end{array}$ & $\begin{array}{l}\text { Respiratory insufficiency, } \\
\text { ventricular fibrillation, }\end{array}$ \\
\hline 6 & C.M. & $\mathbf{M}$ & $\begin{array}{l}\text { Tricuspid } \\
\text { atresia }\end{array}$ & $5 \frac{1}{2}$ & $16 \cdot 100$ & 50 & $\begin{array}{l}\text { Modified Glenn } \\
\text { Azygos ligature }\end{array}$ & Nov. 70 & $\operatorname{con} \mathrm{s}^{2}$ & Survived & \\
\hline 7 & G.S. & $\mathbf{F}$ & $\begin{array}{l}\text { Tricuspid } \\
\text { atresia }\end{array}$ & 5 & 5.000 & 51 & $\begin{array}{l}\text { Modified Glenn } \\
\text { Azygos ligature }\end{array}$ & April 70 & $\begin{array}{l}\text { SVC syndrome; } \\
\text { interstitial }\end{array}$ & $\begin{array}{l}\text { 9th POD² } \\
\text { Died }\end{array}$ & $\begin{array}{l}\text { Progressive irreversible } \\
\text { respiratory insufficiency }\end{array}$ \\
\hline 8 & V.A. & $\mathbf{M}$ & $\begin{array}{l}\text { Tricuspid } \\
\text { atresia }\end{array}$ & 3 & $10 \cdot 200$ & 51 & $\begin{array}{l}\text { Modified Glenn' } \\
\text { Azygos ligature }\end{array}$ & June 70 & $\begin{array}{l}\text { oedema Rt. lung } \\
\text { SVC syndrome } \\
\text { slight }\end{array}$ & Survived $^{3}$ & \\
\hline 9 & P.M. & $\mathbf{F}$ & $\begin{array}{l}\text { Tricuspid } \\
\text { atresia } \\
\text { Turner } \\
\text { syndrome }\end{array}$ & 6 & $15 \cdot 700$ & 56 & $\begin{array}{l}\text { Modified Glenn } \\
\text { Azygos ligature } \\
\text { SVC loop }\end{array}$ & July 70 & $\begin{array}{l}\text { Massive Rt. } \\
\text { broncho- } \\
\text { pneumonia; } \\
\text { haemorrhagic } \\
\text { diathesis? }\end{array}$ & $\begin{array}{l}\text { 12th } \\
\text { POD } \\
\text { Died }\end{array}$ & $\begin{array}{l}\text { Progressive irreversible } \\
\text { respiratory insufficiency }\end{array}$ \\
\hline
\end{tabular}

Angiocardiograph postoperatively. ${ }^{2}$ Unsuccessfully reoperated upon. ${ }^{3}$ Previous systemic-pulmonary anastomosis in other institution POD $=$ postoperative day. 
graphic impression. The second death occurred in a 5-month-o'd patient as a result of severe pulmonary congestion and progressive respiratory insufficiency followed by cardiac arrest. This patient was severely underdeveloped, about $40 \%$ below the expected weight for age and sex. The third death, in a patient aged 6 years with the Turner syndrome, was due to progressive massive bronchopneumonia which led to death on the twelfth postoperative day. In addition, there were diffuse petechial haemorrhages, especially severe over the right chest where they became confluent, indicating a probable haemorrhagic diathesis, the exact nature of which was indeterminable.

No late deaths have been recorded to date. However, one patient fell with loss of consciousness and an undetermined period of hypotension, approximately nine months after the procedure; the following day this patient developed a superior vena cava occlusion syndrome, presumably from an anastomotic occlusion. She has been cared for in another institution and her condition has been reported as improving slowly.

In two of the surviving patients a mild form of superior vena cava syndrome developed in the 48 hours immediately following surgery, in one case with some petechial haemorrhages in the upper chest and neck.

The surgical indications were those of the classically performed Glenn operation.

As can be seen from the Table, the present technique evolved in two stages. At first a side-to-side anastomosis between the right pulmonary artery

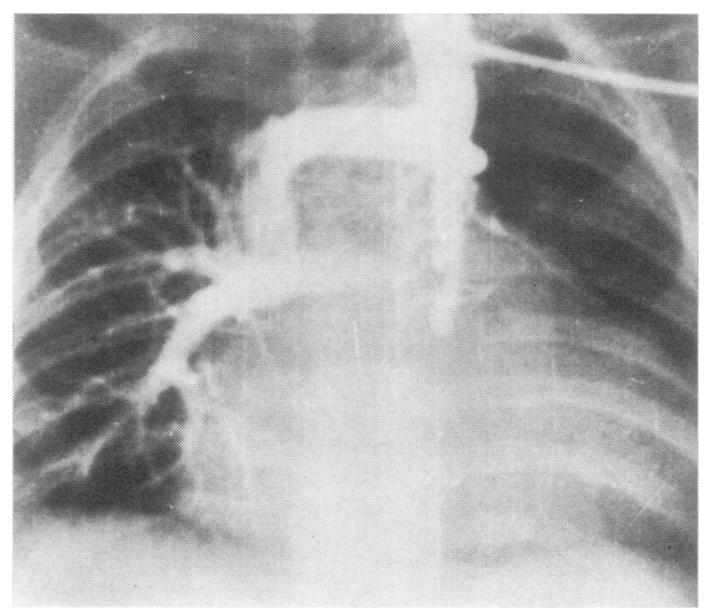

FIG. 6. Patient 3. Two months postoperative angiocardiogram showing patency of the shunt and bilaterality of flow. $A$ collateral from the innominate vein is also present. and superior vena cava was adopted, for the most part associated with ligature of the azygos vein. From June 1970 ligature of the azygos vein became routine together with delayed interruption of the superior vena cava. Closure of the superior vena cava at its entrance into the right atrium has been done according to the described technique of to and fro suture ; latterly one-quarter to one-third of the vessel has been left patent.

In four patients there have been angiocardiographic studies from one to five months after the procedure showing patency of the shunt and bilaterality of pulmonary flow (Fig. 6).

Complications are listed in the Table. None was significant except in those patients who succumbed. Operative mortality was $33 \%$ (three out of nine patients).

The classical Glenn operation with its known modifications (Edwards and Bargeron, 1968) changes the haemodynamics of the lesion in that the superior vena cava blood is directed to the right lung and the inferior vena cava return is delivered to the left heart through the interatrial communication and from there to both the left lung and the systemic circulation. Left ventricular myocardial contraction supplies blood to the left lung. Thus while the right lung receives blood at venous systemic pressure, the left lung obtains its blood flow from left myocardial contraction (systemic arterial pressure). As a result there is considerable imbalance in the distribution and flow of blood between the lungs (Šamánek, Oppelt, Kasalický, and Vořišková, 1969) and in the characteristics of perfusion in the two lungs.

Ideally, a palliative procedure, such as cavopulmonary anastomosis, should produce an improvement in the pulmodynamic state and yet not so distort the anatomy that total corrective surgery would be impossible if such a procedure should be developed in the future.

The main advantages of the illustrated technique are: (1) the right pulmonary artery is not sacrificed, and this may be an advantage should a truly corrective procedure be developed; whenever applied to the treatment of tetralogy of Fallot this advantage is immediate and maximal; (2) owing to the placement of the stoma near or at the bifurcation of the main pulmonary artery, venous blood is directed to both lungs, though predominantly to the right ; (3) removal of a roughly triangular portion of the vessel wall creates an 'open mouth' stoma whose advantage is obvious in permitting maximal flow and reducing the risk of thrombosis in a low pressure system; (4) delayed complete 
closure of the superior vena cava to right atrium communication may avoid or decrease the incidence of postoperative superior vena cava syndrome ; (5) by electively ligating the azygos vein the development of azygos to superior vena cava collateral circulation is avoided; (6) closure of the superior vena cava by means of a to and fro running suture that flattens the vessel, rather than a mass ligature that crimps and annularly constricts it, may turn out to be an advantage should a better procedure be devised requiring the re-establishment of the superior vena cava to right atrium communication.

We have now standardized the procedure as outlined and constantly use a superior vena cava loop after azygos vein ligation. We believe this is a technically easier expedient than looping the azygos vein since the superior vena cava is closer to the anterior chest wall and the thoracic wall in this area is covered by a relatively thin fibromuscular layer. We are certain that improved results will follow the search for better palliation.

\section{REFERENCES}

Carlon, C. A., Mondini, P. G., and De Marchi, R. (1951). Surgical treatment of some cardiovascular diseases (a new vascular anastomosis). J. int. Coll. Surg., 16, 1.

Edwards, W. S., and Bargeron, L. M., Jr. (1968). The superiority of the Glenn operation for tricuspid atresia in infancy and childhood. J. thorac. cardiovasc. Surg., 55, 60. (1970). Palliative surgery of infants with cyanotic congenital heart disease. Surgery, 68, 931.

Glenn, W. W. L. (1958). Circulatory bypass of the right side of the heart. IV. Shunt between superior vena cava and distal right pulmonary artery. Report of clinical application. New Engl. J. Med., 259, 117.

- and Patiño, J. F. (1954). Circulatory by-pass of the right heart. I. Preliminary observations on the direct delivery of vena caval blood into the pulmonary arterial circulation. Azygos vein-pulmonary artery shunt. Yale J. Biol. Med., $27,147$.

Pensa, P., Azzolina, G., and Eufrate, S. (1968). Le soluzioni colloidali a basso peso molecolare (Dextran) nella prevenzione e nella terapia delle trombosi vascolari in malati di cardiopatie congenite cianogene. Atti Accad. med. lombarda, 23, 1343.

Samánek, M., Oppelt, A., Kasalický, J., and Vořišková, M. (1969). Distribution of pulmonary blood flow after cavopulmonary anastomosis (Glenn operation). Brit. Heart J., 31, 511. 